\title{
Reaction of Acetylenedicarboxylic Acid Made Easy: High-Pressure Route for Polymerization
}

Delori, Amit; Hutchison, lan B.; Bull, Craig L.; Funnell, Nick P.; Urquhart, Andrew J.; Oswald, lain D. H.

Published in:

Crystal Growth \& Design

Link to article, DOI:

10.1021/acs.cgd.7b01338

Publication date:

2018

Document Version

Publisher's PDF, also known as Version of record

Link back to DTU Orbit

Citation (APA):

Delori, A., Hutchison, I. B., Bull, C. L., Funnell, N. P., Urquhart, A. J., \& Oswald, I. D. H. (2018). Reaction of Acetylenedicarboxylic Acid Made Easy: High-Pressure Route for Polymerization. Crystal Growth \& Design, 18(3), 1425-1431. https://doi.org/10.1021/acs.cgd.7b01338

\section{General rights}

Copyright and moral rights for the publications made accessible in the public portal are retained by the authors and/or other copyright owners and it is a condition of accessing publications that users recognise and abide by the legal requirements associated with these rights.

- Users may download and print one copy of any publication from the public portal for the purpose of private study or research.

- You may not further distribute the material or use it for any profit-making activity or commercial gain

- You may freely distribute the URL identifying the publication in the public portal 


\title{
Reaction of Acetylenedicarboxylic Acid Made Easy: High-Pressure Route for Polymerization
}

\author{
Published as part of a Crystal Growth and Design virtual special issue Honoring Prof. William Jones and His \\ Contributions to Organic Solid-State Chemistry
}

Amit Delori, ${ }^{* \dagger}{ }^{\dagger}$ Ian B. Hutchison, ${ }^{\dagger}$ Craig L. Bull, ${ }^{\ddagger}$ Nick P. Funnell, ${ }^{\ddagger}$ Andrew J. Urquhart, ${ }^{*}$, and Iain D. H. Oswald ${ }^{*} \dagger+$ (1)

${ }^{\dagger}$ Strathclyde Institute of Pharmacy and Biomedical Sciences, University of Strathclyde, 161 Cathedral Street, G4 0RE Glasgow, U.K. ${ }^{\ddagger}$ Science and Technology Facilities Council, Rutherford Appleton Laboratory, ISIS Neutron and Muon Source, Harwell Oxford, Didcot, Oxon OX11 0QX, U.K.

${ }^{\S}$ Department of Micro- and Nanotechnology, Technical University of Denmark, Ørsteds Plads, Building 345Ø, 2800 Kgs., Lyngby, Denmark

\section{Supporting Information}

ABSTRACT: A breakthrough has been achieved in improving the efficiency of solid-state polymerization of acetylenedicarboxylic acid (ADCA). Traditional solid-state polymerization of ADCA is marked by long exposure times of $\gamma$-radiation $(>10$ days) and very low yields (around 5.5\%). We have been able to perform a reaction to an $n=8$ oligomer, as confirmed by matrix-assisted laser desorption/ionizationtime of flight, in less than $2 \mathrm{~min}$ by employing $\sim 6 \mathrm{GPa}$ of pressure. We have determined the crystal structure of ADCA on increasing pressure to $(5.2 \mathrm{GPa})$ to provide insight into the process of polymerization with Pixel

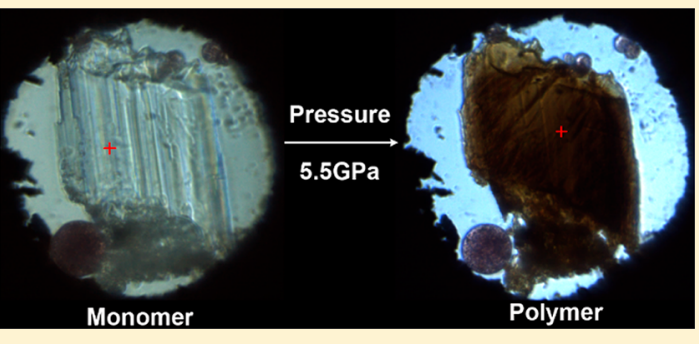
calculations supporting our evaluation of the polymerization process.

\section{INTRODUCTION}

Organic polymers play an important role in day-to-day life (e.g., polyethylene, nylon, Teflon, etc.). Solid state synthesis of polymers is of great interest, as the polymers synthesized by this route might have different architectures and properties compared to those obtained via solution methods. Solid-state synthesis of acetylenes is of special interest as it may selectively form conducting polyacetylene polymers ${ }^{1-4}$ that are used in a range of electronics as much needed components for electronics (e.g., solar cells, organic light emitting diodes etc.). A polymer of acetylene is limited in terms of its solubility and functionality, i.e., lack of functional groups on backbone, and scientists are investigating the formation of various derivatives of polyacetylene using functionalized acetylenes as monomers. One such monomer of interest is the acetylenedicarboxylic acid (ADCA), whose solid-state polymerization is considered a problematic task. Usanmuz et al. attempted solidstate polymerization of ADCA by irradiating it with Co-60 $\gamma$ rays. ${ }^{5}$ No polymer was formed in the first $100 \mathrm{~h}$ over which the sample was exposed to a radiation dose of approximately 2 Mrad. They were able to convert about $5.5 \%$ of monomer to polymer by increasing the total dose of $\gamma$-rays to $70 \mathrm{Mrad}$; however the molecular weight of the polymer was not calculated. The weight was described as high or low depending on the intrinsic viscosity, and they found that over exposure actually shortened the polymer chains by further decom- position of the chains. The authors of the paper suggested that energy in the form of $\gamma$-rays might have helped in bringing together the molecules of ADCA to a more favorable orientation and distance for polymerization. ${ }^{5}$ In the solid state, the molecules can also be brought together by applying pressure, and in this paper we investigated the role of pressure in the polymerization of ADCA. High-pressure techniques are now well-recognized for their potential for the discovery of new solid state forms such as polymorphs, ${ }^{6-20}$ solvates, ${ }^{7,21-23}$ cocrystals, $^{25,26}$ etc. These techniques have also been employed for the polymerization of monomers containing double or triple bonds such as ethylene, ${ }^{24}$ butadiene, ${ }^{25}$ acrylic acid, ${ }^{9,16,26}$ methacrylic acid, ${ }^{16}$ acetylene, ${ }^{27,28}$ phenylacetylene, ${ }^{27-29}$ cyanoacetylene, ${ }^{30}$ cyanogen, ${ }^{31} \mathrm{CO},{ }^{32}$ benzene, ${ }^{33}$ furan, ${ }^{34,35}$ etc. Citroni et al. demonstrated that simultaneous application of laser and pressure can be a great asset and were able to attain selectivity for dimerization versus polymerization for the butadiene system. ${ }^{25}$ The scope of high-pressure polymerizations has been greatly enhanced by their use in ring-opening polymerizations, e.g., triazine, carnosine and L,L-lactide. ${ }^{26,36,37}$ In fact, pressure was used to polymerize some highly stable aromatic molecules such as benzene. ${ }^{33}$ The theory behind these

Received: September 20, 2017

Revised: December 5, 2017

Published: January 22, 2018 
(a)
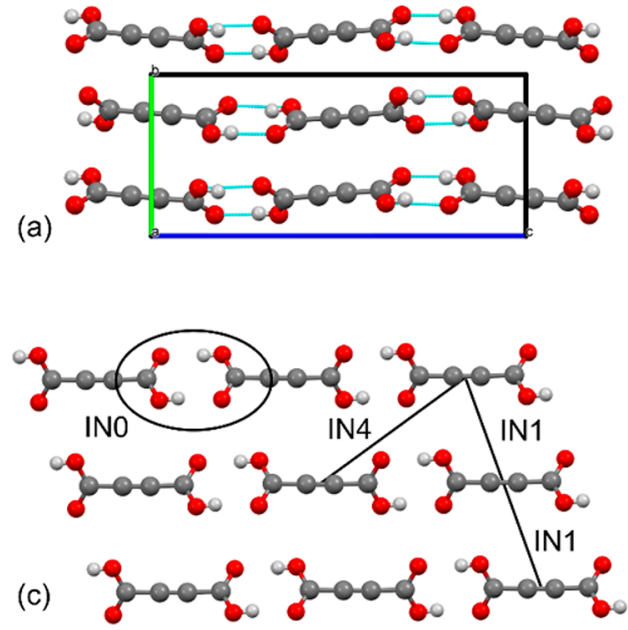

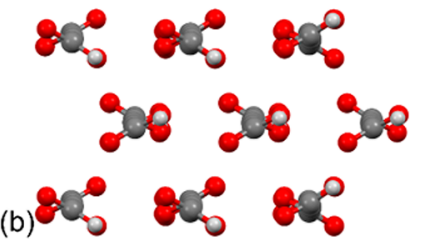

(d)

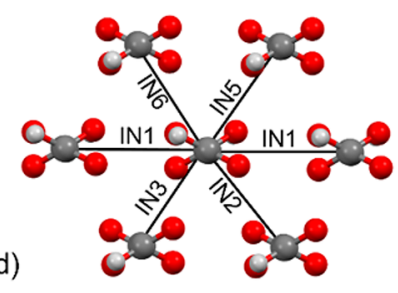

where IN = interaction

Figure 1. (a) A view of packing of the ADCA in the solid state perpendicular to the chains. (b) Packing of the ADCA along the $\left[\begin{array}{lll}1 & 0 & \overline{1}\end{array}\right]$ direction, (c) hydrogen bonding between molecules in the chain and three energetically favorable interactions. (d) Five energetically favorable interactions between the adjacent molecules (IN1-IN5) of particular interest for the polymerization reaction.

solid-state reactions came from Schmidt who proposed the topochemical mechanism based around the distances between the reaction centers. The rule states that the centers should be between 3.6 and $4.1 \AA$ before the reaction can take place. ${ }^{38,39}$ Other theories based on molecular motion were proposed by Kaupp using atomic force microscopy (AFM) to account for the observations that did not obey Schmidt's Rule. ${ }^{40}$

Herein, we discuss the structural changes that occur in ADCA before reaction to the polymer product as well as providing insight into the product of the reaction using matrixassisted laser desorption/ionization-time of flight (MALDITOF).

\section{EXPERIMENTAL SECTION}

Materials Used. ADCA was purchased from Sigma-Aldrich and was recrystallized from acetone. Petroleum ether (35:60) (Alfa Aesar) was used as a pressure-transmitting medium in the high-pressure experiments.

High-Pressure Experiments. High-pressure studies were performed using a Merrill-Bassett diamond anvil cell (DAC) with $600 \mu \mathrm{m}$ culet diamonds glued onto tungsten carbide backing disks. A $250 \mu \mathrm{m}$ thick tungsten foil gasket was indented to $\sim 90 \mu \mathrm{m}$, and a $200 \mu \mathrm{m}$ hole was drilled in the indented portion of the gasket to create a sample chamber. A few rubies were placed in the sample chamber to allow in situ pressure measurement via the ruby fluorescence technique. ${ }^{41}$

For the structure determination by single-crystal X-ray diffraction, we loaded three crystals in different orientations simultaneously together with the rubies. We saw an improvement of 30\% from 54\% completeness to $84 \%$ completeness by using the three crystallites. Data from only two crystals were used for the refinements at 4.29 and 4.85 $\mathrm{GPa}$ as the diffraction from the third crystal was too weak. Due to the potential subtle transition in the ADCA at low pressures, a further data set was collected on a fresh sample at $0.51 \mathrm{GPa}$. For this data set we loaded two crystals and two to three rubies for measuring the crystal structure at a pressure point of $0.51 \mathrm{GPa}$.

Further experiments were conducted to confirm that the color change and polymerization occurred solely with the use of pressure and not initiated with the X-rays or laser $(532 \mathrm{~nm})$. For these experiments the DAC was loaded as above, and pressure was applied only monitoring the sample optically with a microscope. Only once the change of color was observed was the pressure verified using the fluorescence technique.

Raman Spectroscopy. Raman spectra were collected on a Horiba Scientific Jobin Yvon Raman XplorA microscope or a ThermoFisher
DXR microscope fitted with a $532 \mathrm{~nm}$ laser to allow monitoring of both the Raman spectrum and the fluorescence from the ruby. The latter Raman microscope required the use of an extended range grating to observe the ruby fluorescence. Spectra were analyzed using LabSpec6 or Omnic and Origin2015.

Single-Crystal X-ray Diffraction. X-ray diffraction intensities were collected using a Bruker Apex II diffractometer with an Incotec $\mathrm{I} \mu \mathrm{S}$ microsource $(\lambda=0.71073 \AA)$. The diffraction from the three crystals was separated using a reciprocal lattice determination tool and indexed with three separate orientation matrices. The data for each crystal were integrated separately using SAINT in APEX3 software utilizing the in-built dynamic masking procedure. Absorption correction was conducted with SADABS. ${ }^{42}$ After data-processing the data for each crystal at each pressure point were merged in XPREP, culminating in a $30 \%$ improvement in the data completeness; only two crystals were used for pressure points 4.29 and $4.85 \mathrm{GPa}(55 \%$ completeness to $69 \%$ after merging). OLEX2 was used to refine the low temperature model to the high-pressure data sets. ${ }^{43}$ All nonhydrogen atoms were anisotropically refined, and the hydrogen atom was geometrically placed on both oxygen atoms with their occupancies set to 0.5 , which was identified in previous work ${ }^{44,45}$ and supported by our observations. For each data set, some data have been omitted due to overlap with diamond or the beamstop. Crystallographic tables can be found in Table SI1 of the Supporting Information.

Periodic DFT Calculations. Geometry optimizations of Form III were performed by periodic density functional theory (DFT) using the $\mathrm{DMOL}^{3} \operatorname{code}^{46}$ as part of the Materials Studio modeling suite. ${ }^{47}$ The DND numerical basis set ${ }^{46}$ was used in combination with the PBE functional $^{48}$ with the Tkatchenko-Scheffler correction for dispersion. ${ }^{49}$ The unit cell dimensions were held fixed at the values obtained from the single-crystal experiment described above, and coordinates were allowed to optimize. Convergence was defined with medium quality, i.e., when the maximum changes in total energy, displacement, and gradient were $2 \times 10^{-5} \mathrm{Ha}, 5 \times 10^{-3} \AA$, and $4 \times 10^{-3} \mathrm{Ha} \AA^{-1}$, respectively. Brillouin zone integrations were performed by Monkhorst-Pack ${ }^{50} \mathrm{k}$-point sampling at intervals of $0.08 \AA^{-1}$.

Pixel Calculations. Pixel calculations, as incorporated in the CLP suite of programs, were performed on each data set. ${ }^{51,52}$ Ordered models were used for this process; therefore we kept the hydrogen atoms attached to the oxygen with more single bond character. Electron densities were calculated using Gaussian09w ${ }^{53}$ at the MP2/6$31 \mathrm{G}^{* *}$ level. The condensation level was set at the default, 4. Visualization of the interactions was made possible through the use of processPixel. ${ }^{54}$ The energies can be found in Tables SI2-S9 in the Supporting Information. 
Paris-Edinburgh Press. The reaction of ADCA was scaled-up using a Paris-Edinburgh V3 press at ISIS Neutron and Muon Source. ${ }^{55}$ Two samples were prepared: one with pressure-transmitting medium (fluorinert) and the other without any media. Due to the press being situated outwith the instrument, the measurement of pressure was not available; however the load vs pressure characteristics of the cell are reasonably reproducible such that compression to 60 tonnes load would achieve the required pressure of over $5 \mathrm{GPa}$. On achieving this highest load of 60 tonnes, there was a failure in the gasket signifying that a large volume change had occurred in the sample. Both samples showed brown coloration on download with the pure material without the pressure-transmitting medium being slightly darker.

MALDI-TOF. Polymerized ADCA samples from the ParisEdinburgh experiment were dissolved in a chloroform/methanol solution $(4: 1 \mathrm{v} / \mathrm{v})$ and a 2,5-dihydroxybenzoic acid (0.1\% trifluoroacetic acid) matrix was used. Sample mass spectra were acquired on a Bruker Autoflex Speed MALDI-TOF mass spectrometer.

\section{RESULTS AND DISCUSSION}

ADCA is one of the simplest alkyne molecules that possess hydrogen-bonding capabilities. A polymer of ADCA will contain many carboxylic acid functional groups and hence may find applications for the delivery of chemicals such as pharmaceuticals, pigments, agrochemicals, etc. ${ }^{56}$ The carboxylic acid groups of $\mathrm{ADCA}$ are disordered leading to $\mathrm{C}-\mathrm{O}$ distances that are shorter and $\mathrm{C}=\mathrm{O}$ distances slightly longer than normal which confirms previous literature reports. ${ }^{44,45}$ Our refinements fix the occupancy of the hydrogen atoms to be $50 \%$. ADCA forms carboxylic acid dimers (IN0) that continue into chains through the structure along the $\left[\begin{array}{lll}1 & 0 & \overline{1}\end{array}\right]$ direction (Figure 1). These chains form a layer that is offset from those above and below giving a close-packed structure when viewed down the hydrogen-bonded chain length (Figure 1b,d). Each of these chains is surrounded by six neighboring chains (IN1IN5) where the acetylene groups of the molecules are in close proximity to one another, giving rise to the potential formation of a polymer through compression of these interactions (Figure 1d). At ambient pressure the distance between the acetylene groups is approximately $4 \AA$, which is at the top end for reactive center separation proposed by $\mathrm{Schmidt}$ rule for solid-state reactions. ${ }^{38,39}$ In his work, Schmidt realized the importance of distance between the polymerizable groups coining the "Schmidt Rule". According to this rule, for a photodimerization to occur the polymerizable groups should be separated by less than $4 \AA^{38}$ This is in line with our other studies on acrylic acid and those of Goroff et al. ${ }^{57}$ There are a number of solid-state reactions that do not follow this rule as can be found in Kaupp's work. $^{40}$

Initially, we investigated ADCA at high pressure using optical microscopy and Raman spectroscopy to survey any molecular changes in the molecule. We were mindful that the irradiation of the sample using the laser may induce the polymerization as has been observed in other studies; ${ }^{25,58}$ however from the low wavenumber of the Raman spectra it can be seen that there is compression of the structure with little change in the molecular structure. At the highest pressure of $5.04 \mathrm{GPa}$, the bending modes of the carbon chain at $300 \mathrm{~cm}^{-1}$ split, indicating possible conformational changes in the molecular structure (Figure 2a). Alongside this, the crystal became copper colored (Figure $2 b$ ). The change in color occurred even in fresh samples when we monitored thorough microscopy alone; hence the laser was not necessary to induce the chemical reaction. We only validated the pressure after the color change occurred.
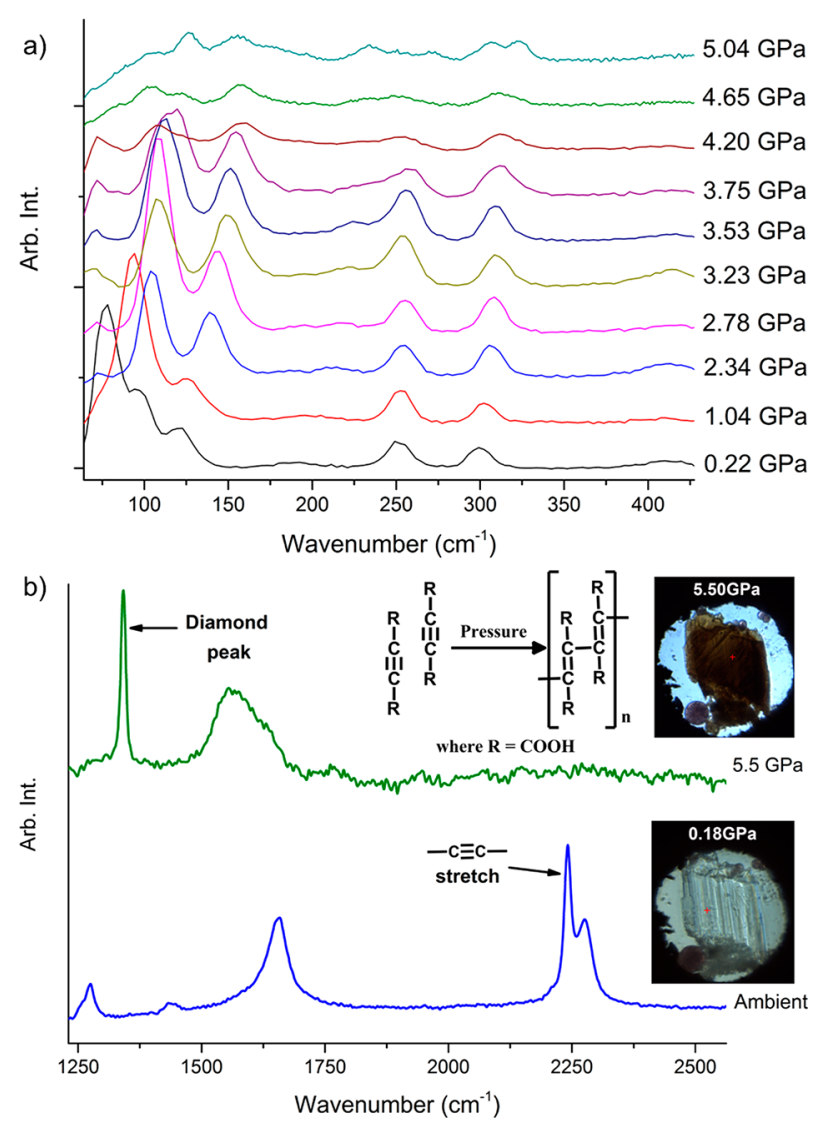

Figure 2. (a) Raman spectra of ADCA on compression to 5.0 GPa. (b) Raman spectra from a separate loading indicating the loss of $\mathrm{C}-\mathrm{C}$ triple bond and the color change exhibited by the crystal above 5.5 GPa.

Following the microscopic and Raman studies, single-crystal $\mathrm{X}$-ray diffraction measurements were conducted on the sample. The diffraction from the three crystals was good; however, one of the crystals was smaller and weakly diffracting and hence was used up to $4.29 \mathrm{GPa}$ before the diffraction was too weak to integrate. The Raman data suggested that there was a transition above $5 \mathrm{GPa}$ to a new phase which is confirmed in the X-ray measurements. However, a more subtle transition is observed at a much lower pressure between 0.51 and $0.98 \mathrm{GPa}$ (Figure 3a).

Form II of ADCA maintains the symmetry of Form I, and the phase transition is only clear due to the discontinuity in the pressure vs volume graph (Figure 3a). The similarity was such that we were able to refine the new phase starting with the model from the low pressure Form I without difficulty. Further confirmation of the phase transition comes from the calculation of the Total Lattice Energy using Pixel ${ }^{51,52}$ which together with the internal change in molecular energy gives the adjusted energy $\left(U_{\text {adj }}\right)$. There is, again, a sharp change over the phase transition (Figure $3 b$ ) that is mainly due to the change in the molecular conformation to a lower energy form.

The equation of state of Form I could not be refined due to the lack of data points, but Form II shows a compressibility that is commensurate with other organic substances ( $\mathrm{K}^{\prime} 14.5(8), \mathrm{V}_{0}$ $450(3) \AA^{3}$ using a second order Birch-Murnaghan equation of state). The compression of Form II is anisotropic with the $c$ axis, the least compressible $(2.8 \%)$ followed by the $a-(8.7 \%)$ and then the $b$-axis $(11.1 \%)$. This can be rationalized from the orientation of the hydrogen bonded chains with respect to the 
a)

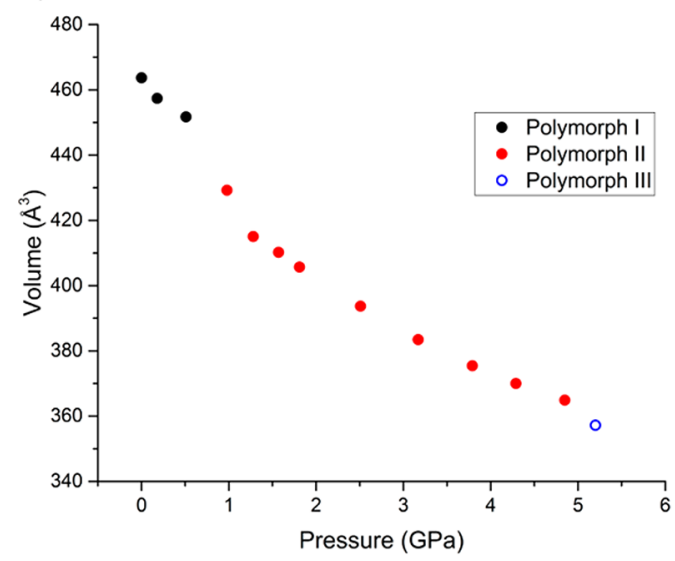

b)

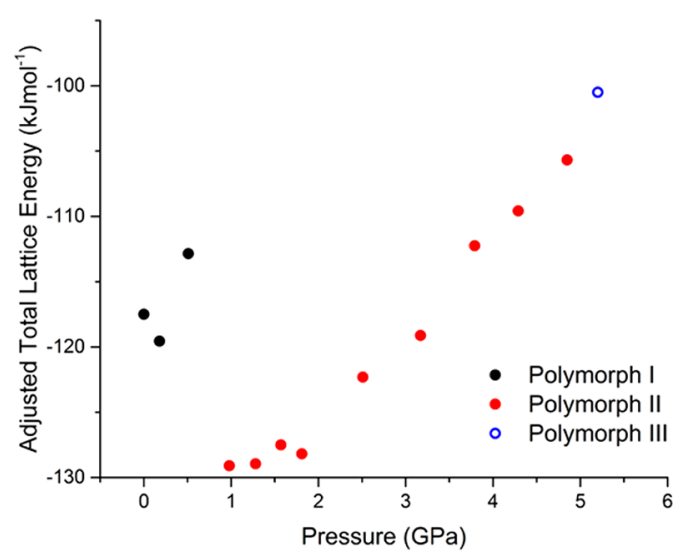

Figure 3. (a) Unit cell compression of ADCA with discontinuities signifying phase transformations. (b) The adjusted lattice energy ( $\left.U_{\text {adj }}\right)$ takes into account the changes in molecular energy as well as the total lattice energy calculated via Pixel. Form III was calculated using a geometry optimized structure.

axes. The direction of the chains $\left[\begin{array}{lll}1 & 0 & \overline{1}\end{array}\right]$ has components of both the $a$ - and $c$-axis; hence the compression along these axes would necessitate the compression of the molecule in these directions. There are no strong hydrogen bonding interactions along the $b$-axis, hence it is the most compressible direction.

For solid-state reactions to occur, the packing of the molecules is crucial and in particular the distance between reaction centers. In the crystal structure of $\mathrm{ADCA}$, it is surrounded by six neighbors, with which it can interact for polymerization using its carbon-carbon triple bond. We have labeled these as interactions 0-5 (IN0-5; Figure 1d). The centroids of the molecules, as used by Pixel, lie on the carbon triple bond and hence serve as a good estimate of the distances between the centers required for polymerization to occur. Figure 4 shows how the energies of interaction change as a function of distance.

The interaction between molecules in the dimer (Int. 0) is the strongest interaction dominated by Coulombic and polarization terms that steadily becomes more repulsive as pressure is applied. The interactions that have the greatest rate

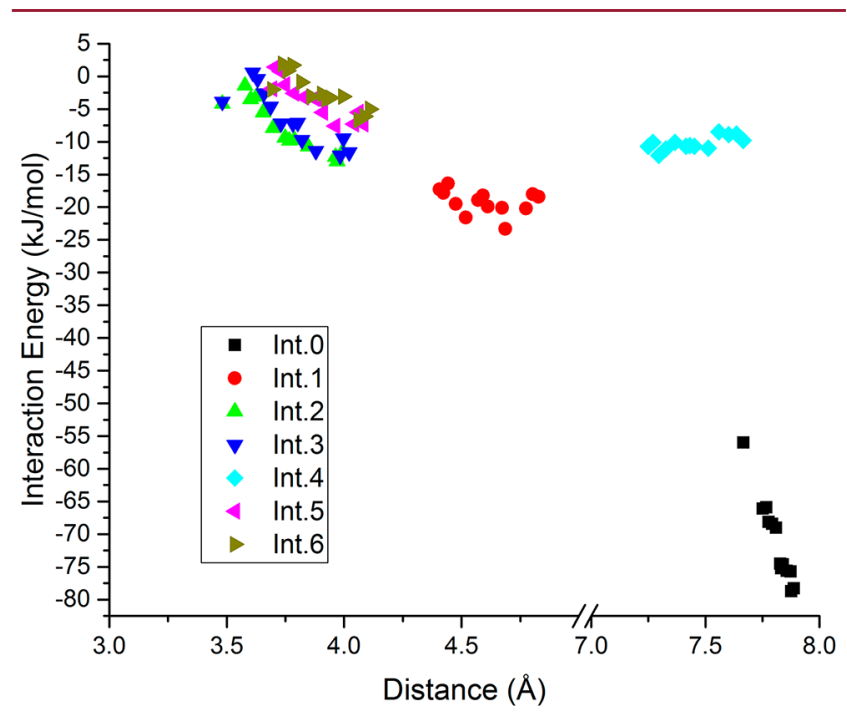

Figure 4. Interaction energies for the top seven interactions in ADCA over the pressure range. Interactions 2 and 3 are notably the closest interactions rapidly becoming repulsive. of compression are Int. 2 and 3, which are more dispersive in character as the molecules interact using van der Waals interactions; these two interactions can be seen in Figure 1d. As we reach the point of reaction the distance of the molecules tends toward $3.5 \AA$, which is close to the ideal distance for polymerization as commented by Schmidt ( $3.58 \AA$ and $3.61 \AA$, respectively), ${ }^{38,39}$ which suggests that these two interactions may be those to initiate that polymerization. Between 4.85 and 5.2 GPa there is a transition to Form III which we were able to identify. The refinement statistics are not as good as the previous data sets; however we have been able to identify a Ccentered cell and solve the structure with $Z^{\prime}=1 / 2$. The residual electron density from this refinement (located at $(0.5118$, $0.4386,0.5828)$ ) is higher than normal and is observed at right angles to the molecules near the acetylene moiety. The direction of the density is toward the molecules involved in Int. 2 and 3 rather that those involved in Int. 5 and 6 . This supports our observations that these two interactions may be where the reaction is initiated. To understand the changes over the transition, we geometry-optimized the structure at $5.2 \mathrm{GPa}$ before performing the Pixel calculations. This was, in part, due to the quality of the data set at $5.2 \mathrm{GPa}$ but also because the refined structure had $Z^{\prime}=1 / 2$, which may have the unintended problem of distorting the molecule due to symmetry constraints rather than through physical changes. Pixel requires a full molecule to compute the energies, and hence we lowered the symmetry back to $P 2_{1} / n$ for this purpose. In Form III we see that the lateral interactions $2,3,5$, and 6 all continue to compress but show a decrease in energy of $\sim 2-4 \mathrm{~kJ} \mathrm{~mol}^{-1}$ to be more stabilizing. However, it is at the repulsive end of the interactions that shows a very large change. Throughout the compression the interaction of the central molecule with one transformed by $1 / 2+x, 3 / 2-y, 1 / 2+z$ shows a steady destabilization but jumps significantly, by $10 \mathrm{~kJ} \mathrm{~mol}^{-1}$, from 6 $\mathrm{kJ} \mathrm{mol}^{-1}$ to $16 \mathrm{~kJ} \mathrm{~mol}^{-1}$ due to the increase in repulsive energy. This interaction (Figure 5) shows the increasing proximity of the carbonyl groups of the carboxylic acid (2.607 $\AA$, from geometry optimized structure). In the original study by Usanmuz et al. they suggested that $\mathrm{CO}$ or $\mathrm{CO}_{2}$ is lost from the structure during the polymerization. The rapid change in repulsion energy between molecules in this interaction may signify the $\mathrm{CO} / \mathrm{CO}_{2}$ loss mechanism. Why the molecules required this amount of force to polymerize may be found in 


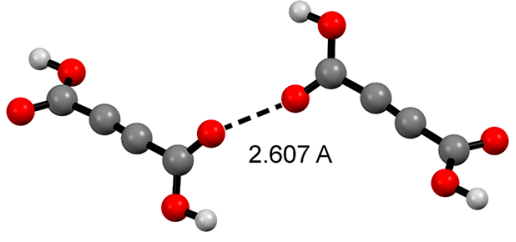

Figure 5. Most energetically unfavorable interaction in Form III of ADCA. The carbonyl-carbonyl interaction measure $2.607 \AA$ in the geometry optimized structure.

the work of Kaupp who proposed that it was the motion of the molecules not the distance between centers that causes the reaction to occur. ${ }^{40}$ With molecules able to move easily (due to the chain structure), we are able to push the molecules closer together and into an arrangement that presets it for the transition-state of the reaction, and hence it facilitates the reaction.

Diamond cells are a very powerful tool for the characterization of materials under high-pressure conditions; however the volume of sample is limited for any subsequent analysis unless it is via spectroscopic or diffraction techniques. Hence we turned to the use of a Paris-Edinburgh press for the compression of a larger volume of sample so that we may analyze the product of the reaction. Two experiments were conducted, with and without pressure-transmitting medium. During one of the compression runs with hydrostatic fluid, we noted a large and sudden decrease in pressure as we reached the highest load of 60 tonnes $(\sim 6 \mathrm{GPa})$ and collapse of the gasket signifying that a large reduction in volume occurred. The compression without fluid also lost pressure but over a greater period of time signifying the reaction. These samples were subsequently characterized using MALDI-TOF which can provide information on the size of the polymers produced; a typical spectrum from these runs is shown in Figure 6. The

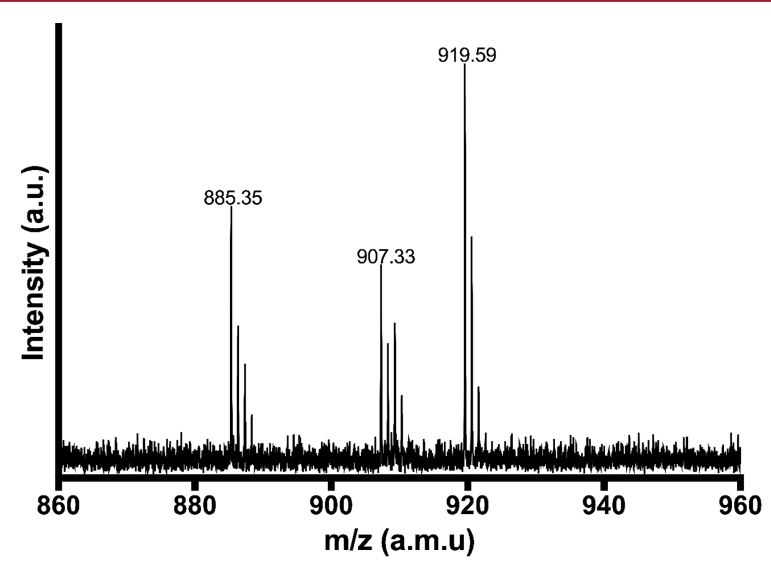

Figure 6. MALDI-TOF spectrum of the largest molecular weights from the samples compressed to 60 tonnes $(\sim 6 \mathrm{GPa})$.

largest mass fragments were observed at 885.35, 907.33, and $919.59 \mathrm{~m} / \mathrm{z}$; lower mass fragments were avoided due to the contribution from the matrix in which the sample sits. The mass at $885.45 \mathrm{~m} / z$ corresponds to $\left[\mathrm{M}_{8}-\mathrm{CO}+\mathrm{H}\right]^{+}$given the mass of the monomer is $114.06 \mathrm{~m} / z$. The mass at $907.33 \mathrm{~m} / z$ corresponds to $\left[\mathrm{M}_{8}-\mathrm{CO}+\mathrm{Na}\right]^{+}$, while the mass at 919.59 corresponds to $\left[\mathrm{M}_{8}-\mathrm{O}+\mathrm{Na}\right]^{+}$. We did not observe any intact $\left[\mathrm{M}_{8}+\mathrm{H}\right]^{+}$fragments, and our results indicate that the ADCA has formed oligomers comprised of eight monomer units but with loss of $\mathrm{CO}$ and $\mathrm{O}$. It may be that heavier fragments did not readily ionize and were therefore not detected. Our observation from the MALDI-TOF that there is loss of CO does match the observations of Usanmaz et al. but via a different reaction route.

The color of the sample from both the diamond cell experiment and large volume experiment may also give us clues to the structure of the oligomers. In the seminal work of Shirikawa on conducting polymers, they noticed that depending on the conformation of the ethylene groups in the polymer, i.e., trans and cis, the color of the polymer was either silver or copper colored. ${ }^{1-3}$ The oligomers that we have produced do show either copper or brown hue rather than the metallic luster, which suggests that these are of the cis form. This corresponds with our observations that Int. 2 and 3 are involved in the polymerization. If we look at the spatial arrangement of the molecules in Figure $1 \mathrm{~d}$, then we can see that by polymerizing in this manner we will end up with the cis rather than trans isomers and hence a copper-colored product.

\section{CONCLUSION}

We have shown that we have been able to induce reaction in ADCA without the use of initiator or significant doses of radiation. The structural information that we have gained through compression has shown that the acetylene moieties are compressed to $\sim 3.5 \AA$ before the reaction occurs. The product of the reaction has been shown to be an oligomer of $n=8$ with loss of $\mathrm{CO}$ and $\mathrm{O}$; however the method of detection may preclude the identification of higher mass fragments. From the color of the samples, we argue that the conformation of the polymer products is of the cis form rather than the trans form.

\section{ASSOCIATED CONTENT}

\section{Supporting Information}

The Supporting Information is available free of charge on the ACS Publications website at DOI: 10.1021/acs.cgd.7b01338.

Crystallographic tables and tables of Pixel energies (PDF)

\section{Accession Codes}

CCDC 1574461-1574473 contain the supplementary crystallographic data for this paper. These data can be obtained free of charge via www.ccdc.cam.ac.uk/data request/cif, or by emailing data_request@ccdc.cam.ac.uk, or by contacting The Cambridge Crystallographic Data Centre, 12 Union Road, Cambridge CB2 1EZ, UK; fax: +44 1223336033.

\section{AUTHOR INFORMATION}

\section{Corresponding Authors}

*(I.D.H.O.) E-mail: iain.oswald@strath.ac.uk.

*(A.D.) E-mail: amitdelori@gmail.com.

*(A.J.U.) E-mail: anur@nanotech.dtu.dk. ORCID

Iain D. H. Oswald: 0000-0003-4339-9392

\section{Author Contributions}

A.D. collected the data sets and produced initial analysis and draft of manuscript. A.J.U. performed the MALDI-TOF experiments and contributed to the manuscript. I.B.H. helped with the high-pressure work. C.L.B. and N.P.F. performed the large volume experiments on ADCA. I.D.H.O. completed the analysis and wrote the final manuscript. 


\section{Funding}

The authors would like to thank The Leverhulme Trust (A.D. and I.D.H.O., RPG-2012-598) and EPSRC (I.B.H., DTC studentship; I.D.H.O., EPN015401-1) for funding. SIPBS is acknowledged for their contribution to the upgrade of the diffractometer to a microsource.

\section{Notes}

The authors declare no competing financial interest. All data underpinning this publication are openly available from the University of Strathclyde KnowledgeBase at http:// dx.doi.org/10.15129/06df23e6-b46e-44fa-bdb7-df5a6ad30bc5.

\section{ACKNOWLEDGMENTS}

We would like to thank Carole Morrison (University of Edinburgh, UK) for useful discussions.

\section{ABBREVIATIONS}

ADCA, acetylenedicarboxylic acid; MALDI-TOF, matrixassisted laser desorption/ionization-time of flight

\section{REFERENCES}

(1) Shirakawa, H. Angew. Chem., Int. Ed. 2001, 40, 2574-2580.

(2) Shirakawa, H.; Ikeda, S. Polym. J. 1971, 2, 231-244.

(3) Shirakawa, H.; Ito, T.; Ikeda, S. Polym. J. 1973, 4, 460-462.

(4) Shirakawa, H.; Louis, E. J.; MacDiarmid, A. G.; Chiang, C. K.; Heeger, A. J. J. Chem. Soc., Chem. Commun. 1977, 578-580.

(5) Usanmaz, A.; Altürk, E. J. Macromol. Sci., Part A: Pure Appl.Chem. 2002, 39, 379-395.

(6) Johnstone, R. D. L.; Lennie, A. R.; Parker, S. F.; Parsons, S.; Pidcock, E.; Richardson, P. R.; Warren, J. E.; Wood, P. A. CrystEngComm 2010, 12, 1065-1078.

(7) Fabbiani, F. P. A.; Allan, D. R.; Marshall, W. G.; Parsons, S.; Pulham, C. R.; Smith, R. I. J. Cryst. Growth 2005, 275, 185-192.

(8) Fabbiani, F. P. A.; Allan, D. R.; David, W. I. F.; Moggach, S. A.; Parsons, S.; Pulham, C. R. CrystEngComm 2004, 6, 504-511.

(9) Johnston, B. F.; Marshall, W. G.; Parsons, S.; Urquhart, A. J.; Oswald, I. D. H. J. Phys. Chem. B 2014, 118, 4044-4051.

(10) Boldyreva, E. V.; Ivashevskaya, S. N.; Sowa, H.; Ahsbahs, H.; Weber, H. P. Dokl. Phys. Chem. 2004, 396, 111-114.

(11) Oswald, I. D. H.; Chataigner, I.; Elphick, S.; Fabbiani, F. P. A.; Lennie, A. R.; Maddaluno, J.; Marshall, W. G.; Prior, T. J.; Pulham, C. R.; Smith, R. I. CrystEngComm 2009, 11, 359-366.

(12) Saouane, S.; Norman, S. E.; Hardacre, C.; Fabbiani, F. P. A. Chem. Sci. 2013, 4, 1270-1280.

(13) Boldyreva, E. Cryst. Growth Des. 2007, 7, 1662-1668.

(14) Moggach, S. A.; Parsons, S.; Wood, P. A. Crystallogr. Rev. 2008, $14,143-184$.

(15) Fabbiani, F. P. A.; Allan, D. R.; Parsons, S.; Pulham, C. R. CrystEngComm 2005, 7, 179-186.

(16) Oswald, I. D. H.; Urquhart, A. J. CrystEngComm 2011, 13, $4503-4507$.

(17) Fabbiani, F. P. A.; Buth, G.; Dittrich, B.; Sowa, H. CrystEngComm 2010, 12, 2541-2550.

(18) Fabbiani, F. P. A.; Allan, D. R.; David, W. I. F.; Davidson, A. J.; Lennie, A. R.; Parsons, S.; Pulham, C. R.; Warren, J. E. Cryst. Growth Des. 2007, 7, 1115-1124.

(19) Oswald, I. D. H.; Allan, D. R.; Day, G. M.; Motherwell, W. D. S.; Parsons, S. Cryst. Growth Des. 2005, 5, 1055-1071.

(20) Hutchison, I. B.; Delori, A.; Wang, X.; Kamenev, K. V.; Urquhart, A. J.; Oswald, I. D. H. CrystEngComm 2015, 17, 1778-1782.

(21) Fabbiani, F. P. A.; Buth, G.; Levendis, D. C.; Cruz-Cabeza, A. J. Chem. Commun. 2014, 50, 1817-1819.

(22) Fabbiani, F. P. A.; Allan, D. R.; Dawson, A.; David, W. I. F.; McGregor, P. A.; Oswald, I. D. H.; Parsons, S.; Pulham, C. R. Chem. Commun. 2003, 3004-3005.
(23) Granero-Garcia, R; Lahoz, F. J.; Paulmann, C.; Saouane, S.; Fabbiani, F. P. A. CrystEngComm 2012, 14, 8664-8670.

(24) Chelazzi, D.; Ceppatelli, M.; Santoro, M.; Bini, R.; Schettino, V. J. Phys. Chem. B 2005, 109, 21658-21663.

(25) Citroni, M.; Ceppatelli, M.; Bini, R.; Schettino, V. Science 2002, 295, 2058-2060.

(26) Murli, C.; Mishra, A. K.; Thomas, S.; Sharma, S. M. J. Phys. Chem. B 2012, 116, 4671-4676.

(27) Trout, C. C.; Badding, J. V. J. Phys. Chem. A 2000, 104, 81428145.

(28) Aoki, K.; Usuba, S.; Yoshida, M.; Kakudate, Y.; Tanaka, K.; Fujiwara, S. J. Chem. Phys. 1988, 89, 529-534.

(29) Sakashita, M.; Yamawaki, H.; Aoki, K. J. Phys. Chem. 1996, 100, 9943-9947.

(30) Aoki, K.; Kakudate, Y.; Yoshida, M.; Usuba, S.; Fujiwara, S. J. Chem. Phys. 1989, 91, 778-782.

(31) Yoo, C. S.; Nicol, M. J. Phys. Chem. 1986, 90, 6732-6736.

(32) Katz, A. I.; Schiferl, D.; Mills, R. L. J. Phys. Chem. 1984, 88, 3176-3179.

(33) Pruzan, P.; Chervin, J. C.; Thiéry, M. M.; Itié, J. P.; Besson, J. M.; Forgerit, J. P.; Revault, M. J. Chem. Phys. 1990, 92, 6910-6915.

(34) Ceppatelli, M.; Santoro, M.; Bini, R.; Schettino, V. J. Chem. Phys. 2003, 118, 1499-1506.

(35) Santoro, M.; Ceppatelli, M.; Bini, R.; Schettino, V. J. Chem. Phys. 2003, 118, 8321-8325.

(36) Citroni, M.; Fanetti, S.; Bini, R. J. Phys. Chem. C 2014, 118, 10284-10290.

(37) Ceppatelli, M.; Frediani, M.; Bini, R. J. Phys. Chem. B 2011, 115, 2173-2184.

(38) Schmidt, G. M. J. Pure Appl. Chem. 1971, 27, 647-78.

(39) Schmidt, G. M. J. J. Chem. Soc. 1964, 2014-2021.

(40) Kaupp, G. CrystEngComm 2003, 5, 117-133.

(41) Piermarini, G. J.; Block, S.; Barnett, J. D.; Forman, R. A. J. Appl. Phys. 1975, 46, 2774-2780.

(42) Sheldrick, G. SADABS, Program for Absorption Correction for Data from Area Detector Frames, version 2008/1, 2008.

(43) Dolomanov, O. V.; Bourhis, L. J.; Gildea, R. J.; Howard, J. A. K.; Puschmann, H. J. Appl. Crystallogr. 2009, 42, 339-341.

(44) Larson, A. C.; Cromer, D. T. Acta Crystallogr., Sect. B: Struct. Crystallogr. Cryst. Chem. 1973, 29, 1579-1583.

(45) Benghiat, V.; Leiserowitz, L.; Schmidt, G. M. J. J. Chem. Soc., Perkin Trans. 2 1972, 2, 1769-1772.

(46) Delley, B. J. Chem. Phys. 1990, 92, 508-517.

(47) Materials Studio Release Notes, Release 6; Accelrys_Software_Inc.: San Diego, 2011.

(48) Perdew, J. P.; Chevary, J. A.; Vosko, S. H.; Jackson, K. A.; Pederson, M. R.; Singh, D. J.; Fiolhais, C. Phys. Rev. B: Condens. Matter Mater. Phys. 1992, 46, 6671-6687.

(49) Tkatchenko, A.; Scheffler, M. Phys. Rev. Lett. 2009, 102, 073005.

(50) Monkhorst, H. J.; Pack, J. D. Phys. Rev. B 1976, 13, 5188-5192.

(51) Gavezzotti, A. J. Phys. Chem. B 2003, 107, 2344-2353.

(52) Gavezzotti, A. Mol. Phys. 2008, 106, 1473-1485.

(53) Frisch, M. J.; Trucks, G. W.; Schlegel, H. B.; Scuseria, G. E.; Robb, M. A.; Cheeseman, J. R.; Scalmani, G.; Barone, V.; Mennucci, B.; Petersson, G. A.; Nakatsuji, H.; Caricato, M.; Li, X.; Hratchian, H. P.; Izmaylov, A. F.; Bloino, J.; Zheng, G.; Sonnenberg, J. L.; Hada, M.; Ehara, M.; Toyota, K.; Fukuda, R.; Hasegawa, J.; Ishida, M.; Nakajima, T.; Honda, Y.; Kitao, O.; Nakai, H.; Vreven, T.; Montgomery, J. A.; Peralta, J. E.; Ogliaro, F.; Bearpark, M.; Heyd, J. J.; Brothers, E.; Kudin, K. N.; Staroverov, V. N.; Kobayashi, R.; Normand, J.; Raghavachari, K.; Rendell, A.; Burant, J. C.; Iyengar, S. S.; Tomasi, J.; Cossi, M.; Rega, N.; Millam, J. M.; Klene, M.; Knox, J. E.; Cross, J. B.; Bakken, V.; Adamo, C.; Jaramillo, J.; Gomperts, R.; Stratmann, R. E.; Yazyev, O.; Austin, A. J.; Cammi, R.; Pomelli, C.; Ochterski, J. W.; Martin, R. L.; Morokuma, K.; Zakrzewski, V. G.; Voth, G. A.; Salvador, P.; Dannenberg, J. J.; Dapprich, S.; Daniels, A. D.; Farkas; Foresman, J. B.; Ortiz, J. V.; Cioslowski, J.; Fox, D. J. Gaussian 09, Revision B.01; Gaussian: Wallingford, CT, 2009.

(54) Bond, A. D. J. Appl. Crystallogr. 2014, 47, 1777-1780. 
(55) Klotz, S.; Besson, J. M.; Hamel, G.; Nelmes, R. J.; Loveday, J. S.; Marshall, W. G.; Wilson, R. M. Appl. Phys. Lett. 1995, 66, 1735-1737. (56) Zhong, Z.; Guo, C.; Chen, L.; Xu, J.; Huang, Y. Chem. Commun. 2014, 50, 6375-6378.

(57) Wilhelm, C.; Boyd, S. A.; Chawda, S.; Fowler, F. W.; Goroff, N. S.; Halada, G. P.; Grey, C. P.; Lauher, J. W.; Luo, L.; Martin, C. D.; Parise, J. B.; Tarabrella, C.; Webb, J. A. J. Am. Chem. Soc. 2008, 130, 4415-4420.

(58) Ceppatelli, M.; Santoro, M.; Bini, R.; Schettino, V. J. Chem. Phys. 2000, 113, 5991-6000. 